\title{
Dança Africana
}

ALMEIDA, Nilson Ferreira de ${ }^{1}$

\section{RESUMO}

O presente trabalho possui como finalidade, a partir de uma perspectiva transversal, dissertar sobre a concepção epistemológicas do território da dança africana, compreendendo desta forma a sua importância dentro da cultura da África, adentrando os caminhos que interpelam a realidade, analisando desta forma os significados da esfera dos movimentos e as suas relações, dando importância para o corpo, os movimentos e os sentidos, entendendo a sua função cultural e a percepção de como habitam o mundo num verdadeiro diálogo crítico entre dança, antropologia e a vida. Com base na Diáspora, compreendese as técnicas, as estéticas e as poéticas oriundas das formas africanizadas de escrita do corpo. $\mathrm{O}$ artigo tem por objetivo evidenciar a dança africana levando ao conhecimento do que elas são na realidade, a razão pela qual se fazem tão presentes no cotidiano dos africanos e os tipos mais comuns reafirmando assim, as diversidades dentro da África e fora dela. A metodologia da pesquisa foi realizada a partir de investigações em páginas eletrônicas, com o intuito de compreender as suas definições, seus contextos e sua importância, reforçando o entendimento sobre elas através de alguns teóricos como Tiérou (2001), Robert Farris-Thompson (1974) e Kariamu Welsh (1985), e dentre outros que reforçam a compreensão dos movimentos da dança africana e do uso do corpo em sua execução.

\section{Dança africana. Cultura.}

\section{African dance}

\section{ABSTRACT}

The present work aims, from a transversal perspective, to talk about the epistemological conception of the territory of African dance, thus understanding its importance within the culture of Africa, entering the paths that challenge reality, thus analyzing the meanings of the sphere of movements and their relations, giving importance to the body, movements and senses, understanding their cultural function and the perception of how they inhabit the world in a true critical dialogue between dance, anthropology and life. Based on the Diaspora, the techniques, aesthetics and poetics that come from Africanized forms of body writing are understood. The article aims to highlight the African dance leading to the knowledge of what they are in reality, the reason why they are so present in the daily lives of Africans and the most common types thus reaffirming, the

\footnotetext{
${ }^{1}$ Mestrando em educação pela Universidade Estadual do Centro-Oeste UNICENTRO/Guarapuava. E-mail: professornil@bol.com.br. Lattes: http://lattes.cnpq.br/4897616847122766. Orcid: https://orcid.org/0000-0003-3140-2099.
}

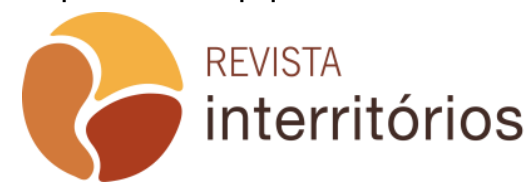


diversities within Africa and outside it. The research methodology was carried out from investigations on electronic pages, in order to understand their definitions, their contexts and their importance, reinforcing the understanding of them through some theorists such as Tiérou (2001), Robert Farris-Thompson (1974) and Kariamu Welsh (1985), and among others who reinforce the understanding of African dance movements and the use of the body in their performance.

African dance. Culture.

\section{Danza africana}

\section{RESUMEN}

El propósito del presente trabajo es, desde una perspectiva transversal, discutir sobre la concepción epistemológica del territorio de la danza africana, entendiendo así su importancia dentro de la cultura africana, adentrándonos en los caminos que desafían la realidad, analizando así los significados de la esfera de los movimientos y sus relaciones, dando importancia al cuerpo, los movimientos y los sentidos, comprendiendo su función cultural y la percepción de cómo habitan el mundo en un verdadero diálogo crítico entre danza, antropología y vida. A partir de la Diáspora se entienden las técnicas, la estética y la poética derivadas de las formas africanizadas de escritura del cuerpo. El artículo tiene como objetivo resaltar la danza africana conduciendo al conocimiento de lo que realmente son, la razón por la que están tan presentes en la vida cotidiana de los africanos y los tipos más comunes reafirmando así, las diversidades dentro y fuera de África. La metodología de investigación se llevó a cabo a partir de investigaciones en páginas electrónicas, con el fin de entender sus definiciones, sus contextos y su importancia, reforzando la comprensión de las danzas a través de algunos teóricos como Tiérou (2001), Robert Farris-Thompson (1974) y Kariamu Welsh (1985), y entre otros que refuerzan la comprensión de los movimientos de la danza africana y el uso del cuerpo en su ejecución.

Danza africana. Cultura.

\section{SOMMARIO}

\section{Danza africana}

Lo scopo di questo lavoro è, da una prospettiva trasversale, discutere la concezione epistemologica del territorio della danza africana, comprendendone così l'importanza all'interno della cultura africana, addentrandosi nei percorsi che sfidano la realtà, analizzando così i significati della sfera dei movimenti e delle loro relazioni, dando importanza al corpo, ai movimenti e ai sensi, comprendendone la funzione culturale e la percezione di come abitano il mondo in un vero dialogo critico tra danza, antropologia e vita. Dalla diaspora si comprendono le tecniche, l'estetica e la poetica derivate dalle forme africanizzate della scrittura del corpo. L'articolo si propone di mettere in luce le danze africane 
portando alla conoscenza di cosa sono realmente, il motivo per cui sono così presenti nella vita quotidiana degli africani e delle tipologie più comuni, riaffermando così le diversità dentro e fuori l'Africa. La metodologia di ricerca è stata realizzata dalla ricerca su pagine elettroniche, al fine di comprenderne le definizioni, i loro contesti e la loro importanza, rafforzando la comprensione delle danze attraverso alcuni teorici come Tiérou (2001), Robert Farris- Thompson (1974) e Kariamu Welsh (1985), e tra gli altri che rafforzano la comprensione dei movimenti della danza africana e l'uso del corpo nella sua esecuzione.

Danza africana. Cultura.

\section{INTRODUÇÃO}

Pensar em dança no universo dos africanos é se deparar com muitas questões pertinentes como: o que são as danças africanas? Por que elas estão tão presentes no cotidiano dos africanos? Quais são os seus tipos? Tais perguntas envolvem uma série de respostas, mas na presente pesquisa pretende-se compreender, dentro de uma abordagem prática-teórica, pensando o seu existir em um percurso que visa redimensionar a importância dos saberes oriundos da diáspora negra nas realidades contemporâneas, dando importância a produção de conhecimento sobre corpo, cultura e dança, compreendendo as suas formas discursivas e seus contextos.

A designação "danças africana" pode ser reconhecida como sendo uma denominação que abrange ao mesmo tempo uma visão artística, política, ritualística e cultural. As danças se espalham para além do continente africano, visto que os povos do Norte da África também são áfricos, mas as suas práticas coreografias se distinguem em muito das danças da antiga África negra, ou seja, aquela parte da África situada ao sul do Deserto do Saara, denominada de subsaariana por estar ao sul do Saara. Neste local as danças se aproximam das danças orientais e árabes.

A dança africana é a repetição do gesto aprendido, dentro da tradição, ou seja, não é uma simples repetição do gesto do professor, mas um conhecimento perfeito do gesto, o que deixa o dançarino livre para improvisar e para responder por gestos e com a sua inspiração ao apelo do Cosmos (TIÉROU, 2001, p. 30).

A designação "dança africana" traz em si um imaginário simbólico, porém muito complexo, que tende a excluir o conjunto de danças que não trabalham a partir dos movimentos locais africanos e patrimoniais, mas sim a partir de uma ideia do que são essas danças. No entanto na atualidade elas divergem em suas formas contemporâneas, que não se concentram especificamente nas danças locais, mas nas danças mais pessoais, mais inventivas e criativas, e isso aconteceu ao longo do tempo por conta das várias influências que tiveram 
durante o tempo, das mais variadas formas de exploração do continente como um todo.

Compreender o que são as danças africanas é adentrar o mundo da pesquisa e de alguns estudiosos que se debruçam a estudá-la. Alguns autores, como Robert Farris-Thompson (1974) e Kariamu Welsh, não as definem, visto que pela diversidade delas no mesmo continente, conceituá-las propriamente seria algo limitante, pela vasta riqueza de ritmos existentes em diversos países, mas caso houvesse que conceituá-las, teriam que se apropriar de um único país africano ou um único ritmo. No entanto, definir estas danças a partir de certas características básicas, a partir de movimentos marcantes existentes em sua maioria podem trazer uma ideia de "dança africana", que caracteriza a sua função dentro do continente.

De acordo com o que Thompson (1974) argumenta, entre diferentes tradições africanas a dança apresenta algumas semelhanças estilísticas. No seu livro denominado "African art in Motion" escrito em 1974, Thompson (1974) apresenta uma análise em torno de eixos comuns e à multiplicidade de formas que se apresentam relacionadas à arte africana. Investigando a estrutura das esculturas, da pintura e, essencialmente da dança, o autor se depara com 50 paralelismos, semelhanças na forma como as diversas etnias africanas se relacionam com o corpo e os movimentos do mesmo. São muitas as regras apresentadas por Thompson (1974), entre elas estão o "efebismo", "contratempo", "multi-métrica", "get down", "looking smart", "entrada e saída apropriadas", "vivacidade através do equilíbrio", "pergunta-e-resposta", "ancestralidade", essencialmente constituindo aspectos relacionados com as qualidades de movimento e tipos de dinâmicas presentes nestas danças.

Dessa forma ao falar de dança africana torna-se relevante pensar em um conjunto de teorias que unificaram as práticas coreográficas africanas. Segundo Thompson (1974), há sete particularidades em comum referentes às formas visuais da arte africana, e especificamente às danças no contexto áfrico: "o policentrismo, a polirritmia, a repetição, as curvas, a dimensionalidade, o sentido holístico e o sentido de passado épico".

A pesquisadora de danças da África e da diáspora africana, Kariamu Welsh Asante (1985), procurou definir características semelhantes nas diversas danças africanas. A autora ressalta que há uma grande dificuldade em classificálas, e isso advém da existência de "uma infinidade de grupos étnicos representando 400 milhões de habitantes no próprio continente e 150 milhões de afrodescendentes na chamada diáspora, espalhada pela América do Sul e do Norte e Pacífico" (WELSH, 2001). O artigo dispõe sobre a existência de sete sentidos estéticos que fazem parte da maioria das danças africanas, que já foram ressaltadas por Thompson (1974), centrando-se na "polirritmia, no policentrismo, na qualidade curvilínea, na dimensionalidade, imitação, memória, repetição e holismo". 
Dentro deste pensamento, Asante (1985) ressalta que é preciso refletir acerca da problemática que define os estilos de dança africana, que têm sido continuamente estereotipados e generalizados. Dessa forma, compreende-se que seria um erro generalizar-la, visto que existem muitas definições possíveis para diferentes ritmos, situações e contextos, nas quais as danças africanas são realizadas, cada uma correspondendo a uma determinada compreensão e função do porquê e quando dançar, elencando também qual a importância da construção de conhecimento do corpo e pelo corpo. A partir desse contexto, compreende-se que a dança esteve sempre presente na história do povo africano devido à preocupação deles com a ligação entre o físico e o espiritual, com os seus antepassados, abrangendo o cuidado com 0 emocional, entretenimento, ritual e a diversão.

Dessa maneira, cabe ressaltar que este trabalho não possui a intenção de encontrar uma definição da dança africana, mas sim propõem-se a pensá-las em sua diversidade, sem se preocupar com as definições universais, se é que existem. Pode-se, sim, em diferentes momentos, identificar algumas danças oriundas de diferentes grupos sociais, dando-Ihes importância para que, assim, se possa compreender a verdadeira riqueza cultural oriunda da África podendo ser encontrada em diferentes países.

\section{A dança no cotidiano dos Africanos}

As danças africanas podem ser consideradas manifestações culturais, no entanto, a maioria dos ritmos dançantes africanos estão ligados à aspectos religiosos. Neste sentido, ao dançar, o corpo se apresenta como uma espécie de ligação entre o mundo espiritual e a terra. Se o Corpo em Diáspora anuncia a conexão com os contextos, não se pode perder de vista a relação intrínseca entre corpo, natureza e universo. A percepção desta ligação pode levar ao despertar de algo fortemente gravado na memória corporal, ou seja, na construção histórica da corporeidade, visto que os ritmos, as danças, os batuques dos africanos tocam a identidade corporal de muitas pessoas.

Paulo Freire, em sua obra "Cartas a Guiné Bissau" (1984), apresenta um exemplo desta ligação, ao tratar a África como um local de costumes que se espalham para várias partes do mundo, mesmo que desprezado pela maioria. $O$ autor comenta que, ao pensar na dança e nos costumes africanos em relação à natureza, percebe-se que permitem realizar um reencontro conosco mesmo, afirmando que, ao se pisar pela primeira vez na África, é possível encontrar as suas matrizes.

A cor do céu, o verde-azul do mar, os coqueiros, as mangueiras, os cajueiros, o gingar do corpo das gentes andando nas ruas, seu sorriso disponível à vida; os tambores soando no fundo das 
noites; os corpos bailando e, ao fazê-lo, 'desenhando o mundo', a presença entre as massas populares, da expressão de sua cultura que os colonizadores não conseguiram matar, me fez perceber que eu era mais africano do que pensava. O quanto foi importante pisar no chão africano e sentir-me nele como quem voltava e não como quem chegava (FREIRE, 1984, p. 13-14).

De acordo com Oliveira (2003), o conhecimento da cultura africana e suas práticas são dependentes dos elementos naturais, já que a relação entre 0 sagrado e a natureza é simbiótica. Na cultura africana, percebe-se que os grupos se organizam para dançar em diferentes situações, momentos específicos dentro de determinada comunidade. Deste modo, compreende-se que as danças africanas são incontáveis em seus estilos, variando conforme os grupos étnicos, ambientes e trocas mútuas através da história das migrações, geralmente realizadas em formas circulares, fileira ou semicírculos, valorizando a participação de todos.

Os momentos em que elas são usadas variam, entretanto, geralmente estão presentes para celebrar algum acontecimento importante, como um casamento, para realizar agradecimentos às divindades e em rituais de passagem, onde celebra-se a morte, seguindo a distintas culturas dos povos de cada região.

O lugar é fundamental na construção da pessoa e da comunidade. A pessoa é construída pela própria comunidade, ela tem seus traços pessoais, na sua forma de organizar as suas influências, tem a sua trajetória, mas o seu pertencimento é uma comunidade. É diferente da ideia de indivíduo (indiviso, aquele que não se divide), na tradição mais ocidental. A pessoa é o contrário, é aquilo que é compartilhado, é o que se compartilha na mesa da amizade, que é o que constitui a comunidade. $E$ essa a perspectiva que dialoga com a tradição ameríndia e com a africana (ALMEIDA, 2012, p. 25).

A dança africana não deve ser vista como igual para todos os países da África, dada a pluralidade de culturas existentes dentro do continente, diferenciando-se de lugar para lugar, um fenômeno universal e, portanto, presente em no mundo todo, pois o homem constrói suas práticas de acordo com os ensinamentos adquiridos ao longo do tempo na sua comunidade, o que sempre se distingue uma das outras.

São variadas as propostas estéticas da dança, bem como as relações que se estabelecem com os acontecimentos e com suas intenções, no entanto, a musicalidade e percussão estão presente em todas elas. É necessário entender que 0 continente africano possui grande variedade de expressões culturais e nem sempre elas acontecem da mesma maneira ou com a mesma intenção em diferentes lugares. Em alguns locais, no momento que acontecem, a dança é acompanhada com instrumentos musicais, porém, muitas das vezes, 
as danças são realizadas apenas com a musicalização das vozes que entoam cantos.

Com os avanços tecnológicos e as influências culturais, as danças africanas foram se modificando, contudo, ela ainda é usada dentro da África como algo importante que descreve a sua cultura, Mauss (1974, p. 217) reforça que "não há técnica e tampouco transmissão se não há tradição". No entanto, para além da aplicabilidade das técnicas, incluindo-se a dança, já que, enquanto fatos sociais, elas podem ser mediações entre categorias de natureza estética, fisiológica, psicológica e cosmológica, no qual o corpo é produtor e produto de processos sociais. Se pensar em noções de tradição e cultura, compreende-se que a dança inevitavelmente incorpora a transformação sociais (MAUSS, 1974).

Na sua maioria, a dança africana está associada a uma estreita relação com a religiosidade, ao passo que muitos dos ritmos dançados são considerados como um elemento de passagem para o mundo espiritual, no qual os africanos acreditam que o participante é levado para outro plano após um transe.

Prova da presença da dança nos rituais fúnebres em alguns locais da África é a Dança do Caixão, criada em Gana, que vem "viralizando" em diversos meios comunicativos, como a internet e a televisão. Em uma reportagem feita pela BBC News (2017), a jornalista Sulley Lansah entrevistou carregadores de caixão de Gana, na África Ocidental, sobre a supramencionada dança, que é realizada em rituais funerais. Durante a entrevista, a repórter comenta que o criador da coreografia foi um agente funerário conhecido como Benjamin Aidoo, que teve a ideia de inserir umacoreografia animada ao trabalho dos carregadores de caixões, como uma novidade aos clientes, que podem escolher entre uma celebração fúnebre solene ou um espetáculo de despedida. Normalmente a música usada é eletrônica: Astronomia 2K19, de Stephan F, mas originalmente, era tocado um jazz africano.

Em Gana, funerais são eventos sociais muito importantes. E recentemente eles têm ganhado um ar mais animado com a popularização dos serviços de carregadores de caixão nada convencionais. Esses profissionais se especializaram em fazer performances de dança durante o evento.

"Quando o cliente vem até nós, perguntamos: 'Você quer algo solene ou um pouco mais de teatro? Ou talvez uma coreografia?", diz Benjamin Aidoo, chefe dos carregadores de caixão.

"É só pedir que nós fazemos."

Aidoo diz ter criado mais de cem empregos para homens e mulheres jovens. Segundo ele, essa é a sua forma de ajudar a diminuir as taxas de desemprego em Gana.

Decidi dar à minha mãe uma viagem dançante até seu criador, afirma Elizabeth Annan, uma das contratantes do serviço. (BBC NEWS, 2017). 
Tradicionalmente, quando a danças tem influência espiritual e dependendo de qual seja este ritual, os movimentos coreográficos devem ser executados com os pés descalços, buscando promover maior ligação do "espírito com a Terra". Neste contexto, as danças africanas podem serem vistas como verdadeiras expressões culturais, artísticas e religiosas, materializadas através dos movimentos do corpo e estando presentes em várias situações, apresentando-se como verdadeiras manifestações inerentes às suas tradições, as quais se perpetuam ao longo do tempo. Sobre o assunto, Defrantz (2004, p. 64) afirma que:

Todas as danças negras da diáspora, incluindo as danças sociais negras, podem ser vistas como semelhantes às linguagens verbais, principalmente no conspícuo emprego da "chamada e resposta", com o corpo respondendo e provocando a voz do tambor.

A dança africana em seus elencos de gêneros e de linguagens corporais são verdadeiras comunicações e memórias da África, as quais transportaram suas heranças para o Brasil e para outros continentes que fizeram uso do processo escravocrata. Em território brasileiro, o corpo negro apresenta-se em suas narrativas gestuais e rítmicas, onde tais gestos e movimentos dançantes tornam-se a base principal para se pensar no universo cultural africano.

O corpo, a música e os batuque brasileiros recriam as memórias dos africanos em terras tupiniquins, visto que mesmo lembrados na condição de escravos e vivendo sobre pressão para seguirem outros costumes, crenças e formas de expressões culturais, deixaram marcas significativas que servem para se pensar que suas raízes são marcantes, a ponto de tornarem-se parte importante da cultura brasileira e possíveis de serem vistas em vivências que revelam a unidade cósmica.

José Gil, (1997, p.26) em "Metamorfoses do corpo", ressalta que o "[...] corpo de uma pessoa possui sentidos, demonstra formas culturais e compreensões de mundo, diferenciadas em cada cultura. É no corpo que se operam mudanças". As danças estão presentes em muitas situações do cotidiano africano, utilizadas para celebrar a vida, motivo mais que importante para se dançar todos os dias. Para eles, vida se renova todos os dias e deve ser celebrada dançando, estando nas rotinas, na arte, nos afazeres cotidianos, nas idas e vindas, nas dores e nas alegrias diárias.

De acordo com Thompson (1974, p. 4), é por esse motivo que "a arte africana transmite a força vital, expressando-se dinamicamente e em movimento". Não é somente as alegrias que levam os africanos dançarem, também às realizando na tristeza. Cerimônias como casamentos, festas típicas, safra abundante, entre tantos outras, são eventos que naturalmente convocam os corpos a movimentarem-se. Assim, as danças acontecem com 0 
acompanhamento de instrumentos musicais tradicionais, ou simplesmente através das palmas das mãos, em círculo ou não, onde é possível perceber os sorrisos estampados nas faces, em olhares que se cruzam, que se encontram, proporcionando cumplicidade, na qual os corpos movimentam-se naturalmente para saldar a vida.

Na obra "Menino Negro", do autor Camara Laye, traduzido por Rosa Freire de d'Aguiar, nota-se claramente a alegria em dançar por algo:

E enquanto meu pai, depois de soldar o grão maior que finalizava a pirâmide, admirava sua obra, o quimbanda, sem poder mais se segurar, enunciava a douga, esse grande canto que só é dirigido aos homens de renome, que só é dançado por esses homens. Diante do enunciado da douga, meu pai se levantava, dava um grito em que se misturavam igualmente triunfo e alegria, e, brandindo com a mão direita seu malho, insígnia de sua profissão, e com a esquerda um chifre de carneiro cheio de substâncias mágicas, dançava a dança gloriosa" (LAYE, 1979, p.31-32).

A supramencionada citação ilustra um momento típico no qual a dança se fez inevitável, relembrando que a tradição reforça o saber ancestral, além de consagrar a cultura e saudar os espíritos protetores como uma forma ritualística de se compreender e agradecer a vida.

Em várias tradições africanas, um recém-nascido é acolhido pelos cantos e pelas danças, já que o nascimento é considerado a verdadeira celebração da vida. Ao contrário, a morte, mesmo sendo um evento triste e que representa 0 fim de uma vida, também suscita cantos e danças. Os cantos e as danças nesse momento podem proporcionar às pessoas a diminuição da dor e, mesmo em momentos difíceis, levam a partilha da tristeza, enquanto que o falecido se encontra em outro plano, no qual, para ele, a morte reflete-se em alegria, já que se reencontrará com seus antepassados, de acordo com sua cultura.

As práticas ligadas à morte potencializam a vida, sendo significativas para o estabelecimento da renovação, ressignificação e reatualização. João Jose Reis (1991, p.138), na obra: "A morte é uma Festa", afirma que os vivos reunidos em solidariedade ao morto, "[...] recuperavam algo do equilíbrio perdido com a visita da morte, afirmando a continuidade da vida".

Dessa forma, compreende-se que os ritos fúnebres em culturas de matriz africana, assim como os demais momentos de passagem, refazem tempos cíclicos, constituem fluxos contínuos e potencializam vivências comunitárias.

\section{Tipos de danças Africanas}


No decorrer dos séculos e a partir do contato com outros povos, as danças africanas sofreram muitas influências, entretanto, ainda é possível dividi-las em dois grupos: as danças tradicionais e as danças modernas.

A dança tradicional africana é aquela que marca práticas tipicamente culturais, estando intrinsecamente ligada à sua tradição, constituindo a história viva da África. As danças tradicionais africanas podem se manifestar como gritos de guerra, que fazem soar o heroísmo, além de poderem representar a sua fé e crenças na espiritualidade, enquanto que outros registram as etapas da vida coletiva ou a passagem da vida para a morte. Seus sons são verdadeiramente linguagens sonoras, carregadas de mensagem repleta de história.

Como exemplo da representação da dança africana tradicional, volta-se a dança em Benin, ou República de Benin, país localizado na África ocidental que traz a marca da cultura africana por estarem ligadas à uma herança ancestral, como movimentos dançantes singulares e específicos. Na maioria dos casos, a dança africana tradicional é organizada em forma de círculos, semicírculos ou fileiras, onde todos podem participar, independentemente da idade ou escala social na comunidade.

A Kpanouhoun é uma dança apresentada em todos os lugares do Benin, especialmente durante eventos especiais do país, como em cerimônias de casamento, formatura, ou quando um futuro casamento da noiva está sendo anunciado. Sobre esse aspecto, Oliveira (2006, p. 129) em sua obra "O NegroAfricano" refere-se a Kpanouhoun da seguinte forma: "Eu sinto o Outro, eu danço o Outro, então eu sou". Ora, dançar é criar, sobretudo quando a dança é dança do amor. É este, em todo o caso, o melhor modo de conhecimento.

Outra dança é a Ogbon, utilizada em cerimônias fúnebres. Abrange todo o Atlântico, mas também é encontrada em outras cidades e vilas do Benin. É uma dança atribuída a fantasmas chamados Egoungoun. Também se tem a Avizinli, que é feita durante o velório e pode ser realizada somente no período da noite. Sato, um outro tipo de dança, também fúnebre, é executada apenas por pessoas sem pai e sem mãe e constitui-se de movimentos em círculo em torno de um tambor grande chamado Tam Tam no Benin, sendo que a sua altura excede a altura do homem, que tentam bater a cabeça no tambor com a ajuda de uma curva, pulando para cima. "A crença na imortalidade do homem explica, em grande parte, a grande importância que a morte e os ritos funerários têm na cosmovisão de mundo africana" (OLIVEIRA, 2003, p. 56).

Sakpata Gambada, Hèbiosso e Atigali são todas danças sagradas, praticadas não apenas durante eventos especiais e são reservadas aos iniciados. As danças conhecidas como Gambada, Djaguidi, Cocoussi, também são reservadas para iniciados, para as mudanças das fases da vida, sendo consideradas sagradas e místicas. 
As danças constituem a evocação de certos episódios da história dos deuses. São fragmentos de mitos, e o mito deve ser representado ao mesmo tempo que falado para adquirir todo o poder evocador" (BASTIDE,1978, p. 22).

Em relação as danças modernas da África, pode-se dizer que elas se relacionam com aquelas oriundas de países europeus ou norte americanos e que foram adotadas pelos africanos, nos quais encontram-se o Hip-Hop, a salsa, o Afro-jazz, entre uma grande infinidade de influências. Elas se aproximam do Movimento Black Power, muito falado no Estados Unidos da América, no qual os negros desejam criar uma estética que reproduzisse o seu cotidiano e suas raízes. O Black Power foi criado por Stokely Carmichael, em 1966, e abrangia a posição de diversos movimentos políticos, culturais e sociais negros dos Estados Unidos, bastante ativos nos anos de 1960 e 1970, e que lutavam contra a segregação racial. A expressão tornou-se mundialmente conhecida nos Jogos Olímpicos de 1968, quando dois atletas negros dos Estados Unidos, Tommie Smith e John Carlos, levantaram os punhos de acordo com a saudação dos Panteras Negras, evidenciando todo poder ao seu povo.

Já Gorer (1981), ressalta que a dança africana moderna coloca o corpo todo em movimento através de uma dinâmica que dispõem sua força propulsiva na bacia, perto do osso sacro. Ao analisar as danças de matrizes africanas em outros países, como no Brasil, por exemplo, percebe-se que há nelas uma pulsação rítmica que é absorvida para esse ponto, ligando a parte alta do tronco do corpo à parte baixa, ou seja, as pernas e os pés. Gorer (1981) ainda ressalta que tal movimento é facilmente observável em danças de rua, foi transformado numa rapidíssima oscilação da bacia.

Mas, nessa mirada de modernidade, o que mais existe é a mistura que a cada dia se torna mais frequente entre os jovens contemporâneos, evidenciando que a música e a dança transitam facilmente entre os ritmos musicais, proporcionando no continente africano como um todo uma variedade de danças. Isso é claramente notável através de movimentos dançantes que marcam dinâmica ritmada nos membros superiores e inferiores. Através do uso de suas articulações ósseas, suas danças apresentam características próprias com movimentos que podem ter se originado das suas ancestralidades, ou seja, da mistura cultural de povos do mesmo continente que caracterizam seus ritmos.

É visível que muitas danças africanas produzem movimentos que partem dos joelhos, que na sua maioria apresentam-se dobrados, porém ritmados com os movimentos dos cotovelos. Dessa forma, obtém-se uma ampliação dos movimentos dos braços e parte da articulação do ombro, harmonizando com os movimentos produzidos pelas pernas que se estendem nos quadris.

Dentro desta dinâmica que contempla a dança africana, é notável no olhar dos dançarinos a presença da disposição de uma forte energia que brota no seu interior. A concentração do dançarino neste momento eleva sua força como se 
ele dançasse em transe. No Brasil, isso é possível de ser visto no sambam, no qual os dançarinos concentram-se interiormente para poder movimentar todo corpo, deixando livre os movimentos da coluna, produzindo o típico tremor do corpo, enquanto que a única expressão facial se concentra no olhar e no sorriso vazio, que revela uma satisfação quase que ritualística, como se elevasse 0 dançarino ao encontro com o sagrado.

Nos anos 60, com o surgimento do Black Arts Movement (Movimento Artístico Negro), surge a dança com consciência social carregada de conteúdo semântico e ideológico. Os dançarinos apresentam um aspecto mais voltado para o estilo rebelde, criando uma mistura de técnicas e estilos contendo diversas culturas, tanto do povo negro quanto do povo branco. Suas maiores inspirações vêm das danças da África e do Caribe, conectadas com a cena urbana contemporânea dos países da América.

Assim como em outras partes do mundo, as danças africanas se misturam com outros ritmos e na África não é diferente, ela tem um efeito de moda, na qual a juventude e os artistas do contexto musical e dançante reinventam ritmos. Entre as modernidades, o que mais se conhece são o Kuduro, o Kizomba, o Afrodanse, o Soyoyo, o Coupé Décalé e o Azonto, que se caracterizam pelos movimentos e expressões que revelam as ansiedades da juventude numa verdadeira busca constante de autoafirmação e de criatividade.

\section{CONSIDERAÇÕES FINAIS}

Ao analisar o universo da dança africana, depara-se com muitos contextos, adentrando a ludicidade, divertimento, culturas, espiritualidade e ancestralidade milenar. Assim, percebe-se o quanto ela está presente em outros continentes, mesmo que muitas vezes seja negada a sua grandeza e sua riqueza.

As suas formas culturais estão engajadas no corpo e o corpo participa ativamente em uma tessitura contínua de detalhe e de movimentos singulares que, mesmo com tanta influência cultural, ela ainda sobrevive na forma em que é dançada. Mesmo que o novo seja acrescentado a ela, é visível suas matrizes pelo corpo que comunica saberes.

O presente trabalho levou a compreensão dos componentes que anunciam a África e sua cultura, a qual estendeu-se pelo mundo através de movimentos dançantes, proporcionando ferramentas e despertando questionamentos sobre seus elementos determinantes, em que a dança apresenta a sua força no campo de produção de saber, os quais foram amplificando-se e pluralizando-se para não submeter seus povos, mesmo muitas vezes escravizados, ao poder daqueles que desejavam excluir sua cultura, seus 
hábitos e sua maneira de trabalhar o corpo de forma expressiva, preservando suas raízes sem deixar universalizar a cultura do branco sobre a dele.

O corpo do negro fala, diferencia e enaltece matrizes ao dançar, que se movimenta, dançando tanto para alegria como para a tristeza, para o físico quanto para o espiritual, com a mesma grandeza, escrevendo sua história, mesmo sem palavras, com os sons de seus instrumentos musicais e pela gestual de seu corpo que fala, que grita saberes. A experiência da referida pesquisa possibilitou interpelar um pouco da história da África através da dança e de suas práticas, proporcionando gerar questionamentos sobre a desvalorização da cultura do povo africano e da valorização de seu corpo.

\section{REFERÊNCIAS}

A história do Kora, instrumento musical com as 21 cordas. Disponível em: http://www.koraawards.com/pt/cultura/a-historia-do-kora/. Acesso em: 06 jun. 2020.

ALMEIDA, Rogerio. Aproximações ao imaginário - bússola de investigação poética. Képos, São Paulo 2012.

ASANTE, Kariamu Welsh. African unity: the rhythm unity. Trenton: Africa World Press, 1990.

ASANTE, Kariamu Welsh. Commonalities in african dance: an aesthetic foundation.

ASANTE, Kariamu Welsh. Zimbabwe dance, rhythmic force, ancestral voices: an aesthetic analysis. Trenton: Africa World Press. 2000.

BBC NEWS. Os carregadores de caixão dançarinos que alegram funerais em Gana. Disponível em: https://www.bbc.com/portuguese/internacional-40734577. Acesso em: 01 jun. 2020.

CAMARA, Laye. O menino negro. Instituto Nacional do Livro e do Disco, 1979.

DEFRANTZ, Thomas F. African American Dance: A Complex History. In:

DEFRANTZ, Thomas F. (org.). Dancing Many Drums: Excavations in African American Dance. Madison: University of Wisconsin Press, 2000.

DEFRANTZ, Thomas F. The Black Beat Made Visible: Hip Hop Dance and Body Power. In: LEPECKI, Andre (Org). Of the Presence of the Body: Essays on Dance and Performance Theory. Middletown, CT: Wesleyan University Press, 2004.

FREIRE, Paulo. Cartas à guiné-bissau.: Paz e Terra, Rio de Janeiro 1984.

FUNGILO, Mario de. Dicionário de Percussão. Fundação da Editora da UNESP, São Paulo. 2002.

GIL, José. Metamorfose do corpo, Relógio D’água, São Paulo 1997. 
Grupo Abayomi. Disponível em: https://grupoabayomi.wordpress.com/quem-somos/. Acesso em: 06 jun. 2020.

LAYE, Câmara. O Menino Negro. Tradução de Rosa Freire d"Aguiar. 1 ed. Seguinte, São Paulo: 2013.

OLIVEIRA, David Eduardo de. Cosmovisão Africana no Brasil: elementos para uma filosofia afrodescendente. Editora Gráfica. Curitiba 2003.

OLIVEIRA, David Eduardo de. Cosmovisão africana no Brasil: elementos para uma filosofia afrodescendente. Curitiba: Editora Gráfica Popular, 2006.

OLIVEIRA, David Eduardo de. Filosofia da ancestralidade como filosofia africana: Educação e cultura afro-brasileira. Revista Sul-Americana de Filosofia e Educação. Número 18: maio-out/2012, p.28-47. Disponível em:

http://seer.bce.unb.br/index.php/resafe/article/view/7029. Acesso em 1 de junho de 2020.

OLIVEIRA, David Eduardo de. Filosofia da ancestralidade: corpo e mito na filosofia da educação brasileira. Curitiba: Editora Gráfica Popular, 2007.

REIS, João José. A morte e uma festa. Campinas Letras. Campinas 1991.

THOMPSON, R. F. African art in motion. Los Angeles: University of California Press, 1974.

TIÉROU, Alphonse. Dooplé: loi éternelle de la danse africaine. Paris: Maisonneuve \& Larose, 1998.

TIÉROU, Alphonse. Si sa danse bouge l'Áfrique bougera. Paris: Maisonneuve et Larose, 2001.

WELSH, Kariamu Asante. African dance. An artistic historical and philosophical inquiry. Eritreia: African World Press, 1998.

WELSH, Kariamu Asante. Commonalities in african dance: an aesthetic foundation. In: DILS, A.; ALBRIGHT, A.C., Moving history/dancing cultures: a dance history reader. Middletown: Wesleyn University Press, 2001. 